\title{
PD-L1 Testing in Cytological Non-Small Cell Lung Cancer Specimens: A Comparison with Biopsies and Review of the Literature
}

\author{
Mohammed S.I. Mansour ${ }^{a}$ b Kajsa Ericson Lindquist ${ }^{c} \quad$ Tomas Seidal $^{a}$ \\ Ulrich Mager ${ }^{d}$ Rikard Mohlin ${ }^{c}$ Lena Tran ${ }^{\mathrm{e}}$ Kim Hejny $^{\mathrm{a}}$ Benjamin Holmgren ${ }^{a}$ \\ Despoina Violidakic Katalin Dobra $^{\mathrm{f}}$ Annika Dejmek ${ }^{\mathrm{g}}$ Maria Planck $^{\mathrm{e}} \mathrm{h}$ \\ Hans Brunnström ${ }^{b, c}$

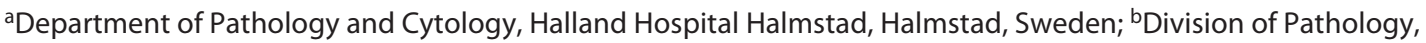 \\ Department of Clinical Sciences Lund, Lund University, Lund, Sweden; 'Department of Genetics and Pathology, \\ Laboratory Medicine Region Skåne, Lund, Sweden; ${ }^{\mathrm{d} D i v i s i o n}$ of Respiratory and Internal Medicine, Department \\ of Clinical Medicine, Halland Hospital Halmstad, Halmstad, Sweden; 'Division of Oncology, Department of \\ Clinical Sciences Lund, Lund University, Medicon Village, Lund, Sweden; fDivision of Clinical Pathology/Cytology, \\ Department of Laboratory Medicine, Karolinska Institute, Karolinska University Hospital Huddinge, Stockholm, \\ Sweden; 9Department of Translational Medicine in Malmö, Lund University, Malmö, Sweden; 'hepartment of \\ Respiratory Medicine and Allergology, Skåne University Hospital, Lund, Sweden
}

\section{Keywords}

$22 \mathrm{C3} \cdot 28-8 \cdot$ Cell block $\cdot$ Cytology $\cdot$ CytoLyt $\cdot$ Histology $\cdot$

PreservCyt

\begin{abstract}
Introduction: Programmed death-ligand 1 (PD-L1) expression is used for treatment prediction in non-small cell lung cancer (NSCLC). While cytology may be the only available material in the routine clinical setting, testing in clinical trials has mainly been based on biopsies. Methods: We included 2 retrospective cohorts of paired, concurrently sampled, cytological specimens and biopsies. Also, the literature on PDL1 in paired cytological/histological samples was reviewed. Focus was on the cutoff levels $\geq 1$ and $\geq 50 \%$ positive tumor cells. Results: Using a 3-tier scale, PD-L1 was concordant in $40 / 47$ (85\%) and $66 / 97$ (68\%) of the paired NSCLC cases in the 2 cohorts, with kappa 0.77 and 0.49 , respectively. In the former cohort, all discordant cases had lower score in cytol-
\end{abstract}

karger@karger.com www.karger.com/acy

Karger $\stackrel{\text { ' }}{=}$

BOPEN ACCESS
(C) 2021 The Author(s)

Published by S. Karger AG, Basel

This is an Open Access article licensed under the Creative Commons Attribution-NonCommercial-4.0 International License (CC BY-NC) (http://www.karger.com/Services/OpenAccessLicense), applicable to the online version of the article only. Usage and distribution for commercial purposes requires written permission. ogy. In both cohorts, concordance was lower in samples from different sites (e.g., biopsy from primary tumor and cytology from pleural effusion). Based on 25 published studies including about 1,700 paired cytology/histology cases, the median (range) concordance was $81-85 \%(62-100 \%)$ at cutoff $1 \%$ for a positive PD-L1 staining and $89 \%(67-100 \%)$ at cutoff $50 \%$. Conclusions: The overall concordance of PD-L1 between cytology and biopsies is rather good but with significant variation between laboratories, which calls for local quality assurance.

(C) 2021 The Author(s) Published by S. Karger AG, Basel

\section{Introduction}

In non-small cell lung cancer (NSCLC), immunohistochemical (IHC) staining for programmed death-ligand 1 (PD-L1) is used to predict response to immune checkpoint inhibitors [1-5]. Different PD-L1 assays have been 
used for the various programmed death-1 (PD-1)/PD-L1 inhibitors, and a lot of studies have presented data on comparison of assays [6-8]. Essentially, the PD-L1 clones 22C3, 28-8, and SP263 (especially the former two) exhibit a similar staining pattern, while SP142 differs from the others. Laboratory-developed tests may give the same results as approved assays, but a highly varying number of laboratory-developed tests have shown inadequate quality [9-11].

Other technical factors may also potentially affect PDL1 staining results. Short fixation time, some decalcification procedures, older paraffin blocks, and long storage time of slides before staining have been linked to reduced staining of tumor cells [12-16]. In contrast, delayed or prolonged formalin fixation has not shown any significant effect on PD-L1 staining $[13,17]$.

Several biological factors that may affect PD-L1 staining results have also been investigated. PD-L1 expression may differ between primary tumor and metastasis with either gain or loss of expression in the metastasis [18-22]. A longer time interval between sampling has been reported to correlate with greater intertumor discrepancy (indicating a change in PD-L1 expression over time) [19], while the metastatic site has been reported not to influence PD-L1 expression [23]. Impact of intratumor heterogeneity has also been explored, and, for example, concordance of PD-L1 expression between paired biopsies and resected tumors has been reported to be $63-92 \%$ for $<1$ versus $\geq 1 \%$ positive tumor cells [24-28].

As immune checkpoint inhibitors are used in advanced and recurrent lung cancer, biopsies have been the main specimen type for PD-L1 evaluation in treatment studies (although resected tumor tissue was also allowed in most) $[1,2,4,5,29-31]$ and is regarded as the gold standard. However, cytology is not seldom the only available material in the clinical setting, and some (e.g., technical) factors may differ between cytological and histological specimens. The aim of the present study was to explore if PD-L1 testing in NSCLC is comparable for cytological specimens and biopsies based on the standard procedures in southern Sweden and to review the current literature.

\section{Materials and Methods}

In the present study, paired cytology/biopsy specimens from NSCLC cases stained with PD-L1 were included from 2 sites in southern Sweden: The Department of Genetics and Pathology in Lund and the Department of Pathology and Cytology in Halmstad.

\section{Study Material}

The 2 cohorts included all available NSCLC cases from 2017 to 2019 in Lund and 2003 to 2019 in Halmstad (the Halmstad cases were all stained in 2016-2020), respectively, with a paired cell block and biopsy stained for PD-L1. For the Lund cohort, all PDL1 stains were from the clinical setting, while for the Halmstad cohort, stains were either from the clinical setting or identically stained as part of the present study.

For both cohorts, only cases where the paired specimens were part of the same diagnostic workup were included ( $<4$ weeks between the samples). Only 1 cell block and 1 biopsy were stained with PD-L1 for each individual, but sometimes the cell block contained material from $>1$ cytological sample, for example, both bronchial brush and endobronchial ultrasound (EBUS)-guided lymph node aspiration combined into a single cell block. Cases with $<100$ evaluable tumor cells in either sample were excluded. Also, 2 cases were excluded where the biopsy and cytology showed different histological types, namely, squamous cell carcinoma and adenocarcinoma (presumably adenosquamous carcinoma) and large cell neuroendocrine carcinoma and adenocarcinoma (either combined large cell neuroendocrine carcinoma or 2 synchronous tumors), respectively. Comparisons of preparation of cytology and PD-L1 staining (including assays) for the 2 cohorts are summarized in Table 1 and are presented in detail in online suppl. material (for all online suppl. material, see www.karger.com/ doi/10.1159/000517078) together with images of control tissue stained for PD-L1 (online suppl. Fig. 1).

\section{PD-L1 Evaluation}

All evaluations were performed using a conventional light microscope. All involved pathologists assess PD-L1 in daily practice. Hematoxylin-eosin-stained sections (and diagnostic IHC staining when performed) were available at time of evaluation of PD-L1. PD-L1 was scored $<1 \%, 1-49 \%$, and $\geq 50 \%$, based on any intensity of partial or complete linear membranous staining of tumor cells in line with assessment manuals (Agilent/pharmDx, Santa Clara, CA, USA) $[32,33]$.

For the Lund cohort, all PD-L1 slides were assessed by at least 2 pathologists. Review was performed as part of the study by pathologists D.V. or H.B. and in most cases also by the pathology resident R.M. Cases were reviewed by all 3 and/or an additional pathologist (K.E.L.) for confirmation when needed.

For the Halmstad cohort, all PD-L1 slides were assessed as part of the study by the certified cytotechnologist M.S.I.M., and one or, when needed, both the pathologists T.S. and H.B. Cases with discordant PD-L1 between biopsy and cytology were also assessed by the pathologist A.D.

As all cases were primarily assessed by 2 investigators, interobserver agreement could be evaluated, although not representing the concordance between the same 2 investigators for all 144 cases. PD-L1 was scored the same by the 2 investigators for 138 biopsies and 131 cytological specimens (no significant difference with Fisher's exact test; kappa 0.93 and 0.86 , respectively).

\section{Statistical Analysis}

Kappa and Wilcoxon signed-rank test were used for diagnostic concordance and comparison of PD-L1 expression, respectively, in the paired cases. Fisher's exact test was used for comparison of concordance between cohorts. The analyses were performed with MedCalc 14.12.0 (MedCalc Software bvba, Ostend, Belgium). 
Table 1. Comparison of fixation and preparation of cytological cell blocks and routine PD-L1 staining for NSCLC for the 2 involved pathology departments (for further details, see online suppl. material)

\begin{tabular}{|c|c|c|}
\hline $\begin{array}{l}\text { Cell block preparation of pleural } \\
\text { effusions }\end{array}$ & $\begin{array}{l}\text { Washed 1-2 times in CytoLyt }{ }^{\circledR}, \text { then }^{\text {tim }} \\
\text { PreservCyt }{ }^{\circledR} 1-3 \text { days, then Cellient } \\
\text { cell block }\end{array}$ & $\begin{array}{l}\text { Formalin fixation of centrifuged pellet in cassette } \\
\text { (bloody samples first washed } \leq 3 \text { times in } \\
\text { CytoLyt }{ }^{\circledR} \text { ) }\end{array}$ \\
\hline $\begin{array}{l}\text { Cell block preparation of other } \\
\text { cytology }\end{array}$ & $\begin{array}{l}\text { CytoLyt }{ }^{\circledR} \text { a few hours, then PreservCyt }{ }^{\circledR} \\
1-3 \text { days, then CellientTM cell block }\end{array}$ & $\begin{array}{l}\text { CytoLyt }^{\circledR} 1-24 \mathrm{~h} \text {, then formalin fixation of } \\
\text { centrifuged pellet in cassette (nodal EBUS } \\
\text { aspirations first in sodium chloride for less than } \\
\text { a few hours) }\end{array}$ \\
\hline PD-L1 staining & 22C3 (Agilent/pharmDx) & 28-8 (Agilent/pharmDx) \\
\hline Staining platform & Ventana Benchmark Ultra & Dako Autostainer Link 48 \\
\hline Control tissue & Tonsil and placenta (on each slide) & $\begin{array}{l}\text { Tonsil, placenta, and either small intestine or } \\
\text { appendix (on each slide); separate slide stained } \\
\text { with negative control reagent; positive and } \\
\text { negative cell lines (in each run) }\end{array}$ \\
\hline PD-L1 analysis of resected tumors & Sometimes performed but not mandatory & Not applicable (no resections) \\
\hline
\end{tabular}

PD-L1, programmed death-ligand 1; NSCLC, non-small cell lung cancer.

\section{Literature Search}

PubMed was searched using "PD-L1 cytology lung cancer" as the search term. Original articles in English until December 2020 that included NSCLC cases with PD-L1 analyzed on cytological material and paired histological specimens were selected. Further articles were identified through the "similar articles" utility of PubMed and individual journals as well as cited references in the retrieved articles. Studies not presenting data for pure cytological versus pure histological specimens were excluded [23, 28, 34-37].

\section{Results}

\section{PD-L1 Concordance}

Concordance of PD-L1 expression in paired biopsies and cytological specimens from NSCLC cases in Lund 2017-2019 and Halmstad 2003-2019 (stained 20162020), respectively, is found in Table 2. As evident, 40 (85\%) of 47 cases (from 47 different individuals) were concordant in the Lund cohort. All discordant cases had lower PD-L1 score in cytology, and the difference in score was significant between biopsies and cytology (Wilcoxon test $p=0.02$ ). Unweighted kappa was 0.77 (95\% CI: $0.62-$ $0.93)$. The concordance was $94 \%$ (44/47) for the $1 \%$ cutoff
Table 2. Concordance of PD-L1 expression in 47 and 97 paired biopsies and cytological specimens from NSCLC, from Lund and Halmstad, respectively

\begin{tabular}{llrc}
\hline Cytology, \% & $<1$ & $1-49$ & $\geq 50$ \\
\hline Lund cohort & Biopsy & & \\
$<1$ & 11 & 2 & 1 \\
$1-49$ & 0 & 11 & 4 \\
$\geq 50$ & 0 & 0 & 18 \\
\hline Halmstad cohort & Biopsy & & \\
$<1$ & 40 & 12 & 2 \\
$1-49$ & 4 & 10 & 7 \\
$\geq 50$ & 0 & 6 & 16
\end{tabular}

PD-L1, programmed death-ligand 1; NSCLC, non-small cell lung cancer.

(i.e., $<1$ or $\geq 1 \%$ positive tumor cells) and $89 \%$ (42/47) for the $50 \%$ cutoff.

In the Halmstad cohort, 66 (68\%) of 97 cases (from 97 different individuals) were concordant, and unweighted kappa was 0.49 (95\% CI: 0.35-0.63). The concordance was $81 \%$ (79/97) for the $1 \%$ cutoff (i.e., $<1$ or $\geq 1 \%$ positive 
Fig. 1. An adenocarcinoma with concordant PD-L1 expression (both $\geq 50 \%$ ) between paired EBUS cytology (a, b) and bronchial biopsy $(\mathbf{c}, \mathbf{d})$. Hematoxylin-eosin (a, c) and PD-L1 clone 22C3 (b, d). Scale bar, $20 \mu \mathrm{m}$. PD-L1, programmed death-ligand 1; EBUS, endobronchial ultrasound.
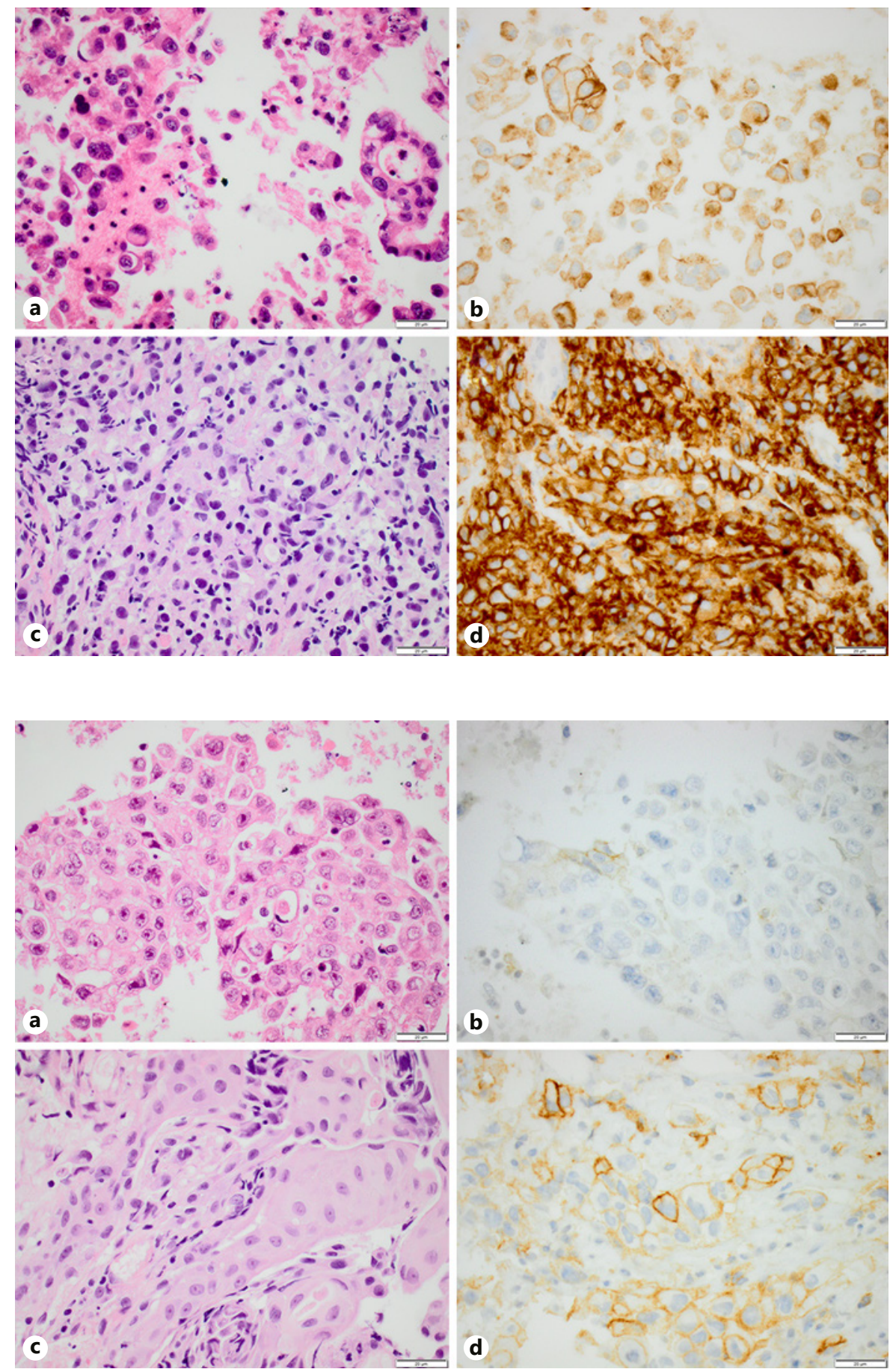

Fig. 2. A squamous cell carcinoma with discordant PD-L1 expression ( $<1 \%$ vs. $\geq 50 \%$ ) between paired EBUS cytology (a, b) and bronchial biopsy $(\mathbf{c}, \mathbf{d})$. Hematoxylin-eosin (a, c) and PD-L1 clone 22C3 (b, d). Scale bar, $20 \mu \mathrm{m}$. PD-L1, programmed death-ligand 1; EBUS, endobronchial ultrasound. tumor cells) and $85 \%(82 / 97)$ for the $50 \%$ cutoff. As evident from Table 2, there were more cases with lower PDL1 score in cytology in the Halmstad cohort, with a nonsignificant trend (Wilcoxon test $p=0.055$ ).

The number of concordant cases was significantly lower in the Halmstad cohort compared to the Lund co- hort (Fisher's exact test $p=0.043$ ). See Figures 1 and 2 for examples of a concordant and a discordant case (using the 3 -tier scale $<1 \% / 1-49 \% / \geq 50 \%$ ), respectively, and online suppl. Figures 2 and 3 for additional cases. 


\section{Characteristics of the Specimens}

The diagnosis of the 47 cases in the Lund cohort was adenocarcinoma in 32 (whereof 29 concordant PD-L1), squamous cell carcinoma in 13 (9 concordant), and NSCLC not otherwise specified in 2 cases (both concordant). The biopsies were bronchial biopsies in 42 cases, transthoracic core biopsies in 3 cases, liver biopsy in 1 case, and biopsy from a cervical lymph node in 1 case. The cytological specimens were bronchial brush in 13 cases, other bronchial cytology including suction catheter, bronchoalveolar lavage (BAL), or mix of any of the two with bronchial brush in 5 cases, EBUS-guided lymph node aspirations in 15 cases, mix of EBUS from lymph nodes and bronchial cytology in 12 cases, and pleural effusions in 2 cases.

The samples were from the same site in 18 cases (whereof 16 concordant PD-L1), partly from the same site in 12 cases ( 11 concordant), or from different sites in 17 cases (13 concordant), respectively. The samples from the same site were all from the primary tumor. The samples partly from the same site were biopsies from the primary tumor and mixed cytological specimens (all mixed bronchial cytology and EBUS from lymph nodes).

The diagnosis of the 97 cases in the Halmstad cohort was adenocarcinoma in 67 (whereof 43 concordant PDL1) and squamous cell carcinoma in 30 cases ( 23 concordant). The biopsies were bronchial biopsies in 62 cases and transthoracic core biopsies in 35 cases. The cytological specimens were bronchial brush in 13 cases, BAL in 53 cases, both bronchial brush and BAL in 7 cases, pleural effusion in 17 cases, EBUS-guided lymph node aspirations in 2 cases, fine-needle aspiration (FNA) of the lymph node in 2 cases, and both BAL and either pleural effusion, EBUS, or FNA of the lymph node in 1 case each.

The samples were from the same site in 73 cases (whereof 54 concordant PD-L1), partly from the same site in 3 cases (all concordant), or from different sites in 21 cases ( 9 concordant), respectively. The samples partly from the same site were biopsies from the primary tumor and mixed cytological specimens (mixed BAL and either pleura, EBUS, or FNA of the lymph node). The paraffin blocks had been stored for at least 3 years before PD-L1 staining in 36 of the cases (whereof 25 concordant PD-L1) and shorter than 3 years in the remaining 61 cases (41 concordant).

\section{Literature Data}

Based on 25 published studies, the mean, median, and range for PD-L1 concordance in studies on paired cytology/histology cases were $83-85 \%, 81-85 \%$, and $62-100 \%$, respectively, at cutoff $1 \%$ for a positive PD-L1 staining and $87-89 \%, 89 \%$, and $67-100 \%$, respectively, at cutoff $50 \%$ [38-62]. The reason for the intervals (here and below) is that some studies presented separate data for $>1$ cytological preparation, PD-L1 assay, or histological specimen type. The numbers remained the same if the data from the present study were included. For further details on individual studies, see online suppl. Table 1.

Summation of all paired cytology/histology cases in the studies (including the cases from the present study) resulted in a concordance of $82-83 \%(1,465 / 1,785-$ $1,488 / 1,792$ cases) at cutoff $1 \%$ for a positive PD-L1 staining and $88-89 \%(1,398 / 1,587-1,408 / 1,580$ cases $)$ at cutoff $50 \%$ [38-62]. If excluding studies with resections, 6 studies (including the present) remained, reporting a concordance in paired cytology/biopsy cases of $81-86 \%$ (228/283-248/290 cases) at cutoff $1 \%$ for a positive PD-L1 staining and $86-90 \%(249 / 290-254 / 283$ cases) at cutoff $50 \%[41,43,46,49,59]$.

In studies with cytology fixed in formalin, that is, excluding studies with nonformalin or mixed formalin/ nonformalin fixation, the concordance with paired histological specimens was $81-82 \%$ (333-336/410 cases) at cutoff $1 \%$ and $88-89 \%(316-317 / 358$ cases $)$ at cutoff $50 \%$ based on 7 studies $[38,39,48,50,58,60,62]$. If instead, only including studies with cytology fixed in nonformalin fixatives, excluding mixed formalin/nonformalin fixation, the concordance with paired histological specimens was $79-81 \%(500-512 / 633$ cases $)$ at cutoff $1 \%$ and $88-$ $89 \%$ (554-565/633 cases) at cutoff $50 \%$ based on 9 studies including the Lund cohort from the present study $[41,45$, $46,49,52,55,56,62]$.

The concordance in studies using only cytological cell blocks compared to histology was $82-84 \%(1,181 / 1,436-$ $1,217 / 1,443$ cases $)$ at cutoff $1 \%$ and $88-89 \%(1,085 / 1,238$ $1,091 / 1,231$ cases) at cutoff $50 \%$ based on 23 studies including the present [38-44, 47-51, 53-62]. Correspondingly, the concordance for cytological smears versus histology was $79-80 \%(327-329 / 413$ cases) at cutoff $1 \%$ and $93 \%(383-384 / 413)$ cases at cutoff $50 \%$ based on 5 studies [43, 45, 46, 49, 52].

\section{Discussion}

The paired cytology/biopsy NSCLC cases of our study support that PD-L1 expression is lower in cytological specimens, with significance in one and trend in the other of our 2 cohorts. Indeed, the PD-L1 score was lower in the cytological specimen for all discordant cases in the 
Lund cohort. It is noteworthy that the concordance was quite limited in the Halmstad cohort, with a kappa value of 0.49. Although discordant expression was more common in paired samples from different sites (e.g., biopsy from the primary tumor and cytology from pleura or lymph nodes) with $58 \%$ concordance ( $22 / 38$ cases) in our 2 cohorts combined, discordant cases were also observed in paired samples from the same site (concordance 77\%; 70/91). Concordance was similar for adenocarcinomas and squamous cell carcinomas and for new and archival blocks.

An important difference between, but also within, our 2 cohorts was the time in alcohol-based fixative (typically 1-3 days vs. $<24 \mathrm{~h}$, but also some with only formalin fixation) and the use of Cellient ${ }^{\mathrm{TM}}$ versus manual cell blocks. While fixation and processing of biopsies is essentially the same at all pathology departments, there are substantial differences in handling of cytological specimens for IHC. Apart from formalin, cells may be fixed in various ethanol- or methanol-containing liquids (e.g., CytoLyt ${ }^{\circledR}, \mathrm{Cy}$ toRich $^{\mathrm{TM}}$ Red, Novaprep ${ }^{\circledR}$, and PreservCyt ${ }^{\circledR}$ ), while different techniques such as direct smears, Cytospin ${ }^{\mathrm{TM}}$ preparations, or cell blocks (e.g., plasma-thrombin, agar, Cellient $^{\mathrm{TM}}$, and Shandon ${ }^{\mathrm{TM}}$ ) may be used [63], also evident from the published studies compiled in online suppl. Table 1 .

Alcohol fixation of tissue has been suggested to affect PD-L1 staining negatively [14], and some studies, like our Lund cohort, report a lower PD-L1 score for alcoholfixed cytology in all discordant paired cytology/histology cases [45, 64]. Also, Koomen et al. [62] clearly demonstrated that alcohol-fixed Cellient ${ }^{\mathrm{TM}}$ cell blocks result in lower concordance with histology compared to formalinfixed agar-based cell blocks. However, the compiled literature data did not show any obvious difference between formalin and nonformalin fixation. Also, Lou et al. [60] presented a very good concordance for formalin-fixed cell blocks with or without prefixation with CytoLyt ${ }^{\circledR}$ [60], while a perfect concordance was seen in the study by Gosney et al. [65] with EBUS cytology fixed in formalin versus alcohol. Fixation in, for example, CytoLyt ${ }^{\circledR}$, is very rapid, and it has been suggested that $<1$-h fixation has no effect on IHC staining (personal communication). The area thus merits future investigation.

Furthermore, specimen types differed between our cohorts, with more bronchial biopsies, brushes, and EBUSguided lymph node aspirations in the Lund cohort, while the Halmstad cohort contained more transthoracic core biopsies, BAL, and pleural effusions. Both, but especially the Lund cohort, contained cell blocks mixed from differ- ent cytological samples (for increased tumor cell content). This complicates analyses of sample types but reflects the real-world diagnostic situation in our setting.

Grosu et al. [50] and Zou et al. [57] showed a higher concordance for PD-L1 in pleural effusions compared to matched histological samples (87-97\% at $1 \%$ cutoff) than did Yoshimura et al. [37] and Jug et al. [58] for EBUSguided samples $(70-84 \%)$. Such a trend is not seen when comparing our 2 cohorts but may be concealed by other differences with greater impact. There were too few pleural effusions in the Lund cohort and too few EBUS-guided aspirations in the Halmstad cohort for comparisons of these 2 sample types within each cohort.

Interestingly, in the Halmstad cohort, biopsy/cytology PD-L1 concordance was lower for bronchial brushes and pleural effusions than for BAL specimens, while there was no obvious difference between bronchial and transthoracic core biopsies. However, our cohorts do not contain enough cases for adequate multivariable analyses, and ideally future studies may include multiple samples from the same patient for further analysis of potential effect of sample type on PD-L1 expression.

Still, the overall concordance of PD-L1 expression between cytology and histology was rather good based on our results and previously published studies. In the literature, discordant cases typically show either higher score in cytology or in histology $[39,42,43,55,66]$, which is expected due to heterogeneity of PD-L1 expression [24-28, 67]. However, the range of concordance was quite broad, $62-100 \%$ at cutoff $1 \%$ and $67-100 \%$ at cutoff $50 \%$ based on 25 publications. Also, several studies present a positive PD-L1 expression $(\geq 1 \%)$ in $<40 \%$ of NSCLC cases when using cytology $[41,42,44,52,54,61,68,69]$, which is notably lower than what has been reported in both early treatment studies and large studies with real-life data, with PD-L1 $\geq 1 \%$ in $53-86 \%$ [70] and 56-63\% [71, 72] of NSCLC, respectively (61\% for cytology [71]). Furthermore, for example, the large study by Kuempers et al. [52] showed a high concordance (93\%) at the $50 \%$ cutoff for a positive staining, but still no case with $>50 \%$ in both cytology (mainly imprints from resections) and the paired resected tumors, which makes the applicability of the results questionable. We believe it would be reasonable for any department that use cytology for PD-L1 to (a) investigate the proportion of PD-L1-positive NSCLC in 50-100 nonselective cytological specimens and (b) evaluate the concordance between biopsies and cytological specimens in $20-30$ paired cases. A lab with $<55 \%$ PD-L1-positive cases and/or concordance $<85 \%$ should consider investigating possible causes and potential improvements. 
Biopsies are currently the standard for PD-L1 testing. However, based on histology, PD-L1 is not considered an optimal predictor of immunotherapy response $[1-5,29$ 31]. Also, there is a variation of positive PD-L1 expression between studies for biopsies as well (e.g., see online suppl. Table 1, but also seen in treatment studies [70]). Thus, it may be argued that the predictive value of PD-L1 in cytology (and preferably also the concordance with biopsies) should be evaluated in a population of patients treated with immunotherapy. Such studies are missing today.

PD-L1 expression in immune cells, relevant for a different PD-L1 assay (SP142), was not a focus of the present study. The representation of tumor-infiltrating immune cells in small samples has been discussed, and the interobserver concordance for PD-L1 has been shown to be low for immune cells [6, 7]. We noted in our Halmstad cohort that $>1 \%$ positive lymphocytes were seen in $7(7 \%)$ of 94 and $>1 \%$ positive macrophages in $60(65 \%)$ of 93 cytological specimens.

Some strengths and weaknesses of the present study must be discussed. Importantly, our paired samples were from the same diagnostic workup, which eliminates any potential effect of systemic therapy and time on PD-L1 expression, and only biopsies (not resections) and cases with $>100$ evaluable tumor cells were included. We did not limit the material to cases with sampling from the same site to eliminate another potentially confounding factor, but data for samples from the same and different sites, respectively, are presented. All cases in each cohort were stained with the same marker, $28-8$ or $22 \mathrm{C} 3$, respectively. As very similar staining patterns have been reported for these $2 \mathrm{PD}-\mathrm{L} 1$ clones [6-8], the staining is probably comparable. The Halmstad cohort contained some old archival cases (which is linked to lower PD-L1 expression and not recommended $[7,15])$, but this was about equal for the cell blocks and biopsies, which probably limits the impact on the results. In the Lund cohort, there was a slight selection bias for PD-L1-positive cases as a cytological cell block was not ordered as often in the clinical setting when a biopsy was PDL1 negative. However, this probably does not affect the results significantly. The inclusion of cell blocks with mixed material from different sites limits the possibility to fully evaluate any possible impact of the sampling site on PD-L1. Also, it may be of note that interobserver discrepancy was $17 \%(3 / 18)$ for these cell blocks compared to $8 \%$ $(10 / 126)$ for the remaining cases.

In conclusion, there is a rather good concordance for PD-L1 expression in NSCLC between cytology and histology, but with quite substantial variation between studies. As fixatives and preparation techniques for cytology may probably affect $\mathrm{PD}$-L1 expression, it is of importance that each laboratory's quality of PD-L1 staining in cytology is kept high, preferably by ascertaining a good correlation with biopsies.

\section{Acknowledgment}

The authors wish to thank the cytology units at the Department of Genetics and Pathology, Lund, and at the Department of Pathology and Cytology, Halmstad. The study was supported by the Regional Agreement on Medical Training and Clinical Research (ALF), Regional Research and Development Funding (FoU), and the Swedish Cancer Society.

\section{Statement of Ethics}

The study was conducted in adherence to the Declaration of Helsinki and was approved by the Regional Ethical Review Board in Lund (Dnr 2019-04782 and Dnr 2006-399 with addition 2017708, respectively).

\section{Conflict of Interest Statement}

The authors have no conflicts of interest to disclose.

\section{Funding Sources}

The study was supported by the Regional Agreement on Medical Training and Clinical Research (ALF), Regional Research and Development Funding (FoU), and the Swedish Cancer Society. The funding sources had no role in the design or conduct of the study.

\section{Author Contributions}

M.S.I.M., T.S., D.V., K.D., A.D., M.P., and H.B. planned the study. L.T. and K.H. performed staining. M.S.I.M., K.E.L., T.S., U.M., R.M., B.H., D.V., A.D., and H.B. collected data. M.S.I.M. and H.B. analyzed the data and wrote the manuscript, and all other authors revised the manuscript for its intellectual content.

\section{References}

1 Herbst RS, Baas P, Kim DW, Felip E, PérezGracia JL, Han JY, et al. Pembrolizumab versus docetaxel for previously treated, PD-L1positive, advanced non-small-cell lung cancer (KEYNOTE-010): a randomised controlled trial. Lancet. 2016;387:1540-50.

2 Reck M, Rodríguez-Abreu D, Robinson AG Hui R, Csőszi T, Fülöp A, et al. Pembrolizumab versus chemotherapy for PD-L1-positive non-small-cell lung cancer. N Engl J Med. 2016;375:1823-33. 
3 Mok TSK, Wu YL, Kudaba I, Kowalski DM, Cho BC, Turna HZ, et al. Pembrolizumab versus chemotherapy for previously untreated, PD-L1-expressing, locally advanced or metastatic non-small-cell lung cancer (KEYNOTE-042): a randomised, open-label, controlled, phase 3 trial. Lancet. 2019;393:181930.

4 Antonia SJ, Villegas A, Daniel D, Vicente D, Murakami S, Hui R, et al. Durvalumab after chemoradiotherapy in stage III non-smallcell lung cancer. N Engl J Med. 2017;377: 1919-29.

5 Antonia SJ, Villegas A, Daniel D, Vicente D, Murakami S, Hui R, et al. Overall survival with durvalumab after chemoradiotherapy in stage III NSCLC. N Engl J Med. 2018;379: 2342-50.

6 Lantuejoul S, Damotte D, Hofman V, Adam J. Programmed death ligand 1 immunohistochemistry in non-small cell lung carcinoma. J Thorac Dis. 2019;11:S89-101.

7 Lantuejoul S, Sound-Tsao M, Cooper WA, Girard N, Hirsch FR, Roden AC, et al. PD-L1 testing for lung cancer in 2019: perspective from the IASLC pathology committee. J Thorac Oncol. 2020;15:499-519.

8 Koomen BM, Badrising SK, van den Heuvel MM, Willems SM. Comparability of PD-L1 immunohistochemistry assays for non-small cell lung cancer: a systematic review. Histopathology. 2020;76:793-802.

9 Scheel AH, Baenfer G, Baretton G, Dietel M, Diezko R, Henkel T, et al. Interlaboratory concordance of PD-L1 immunohistochemistry for non-small-cell lung cancer. Histopathology. 2018;72:449-59.

10 Adam J, Le Stang N, Rouquette I, Cazes A, Badoual C, Pinot-Roussel H, et al. Multicenter harmonization study for PD-L1 IHC testing in non-small-cell lung cancer. Ann Oncol. 2018;29:953-8.

11 NordiQC. PD-L1. Available from: https:// www.nordiqc.org/epitope.php?id=107: NordiQC; 2018 (Accessed 2021 Jan 13).

12 Sato Y, Fujimoto D, Uehara K, Kawachi H, Nagata K, Nakagawa A, et al. Reduced tumour proportion scores for programmed cell death ligand 1 in stored paraffin tissue sections. Anticancer Res. 2018;38:1401-5.

13 Forest F, Cote G, Laville D, Da Cruz V, Dal $\mathrm{Col} P$, Camy F, et al. Impact of delayed fixation and decalcification on PD-L1 expression: a comparison of two clones. Virchows Arch. 2019;475:693-9.

14 Roche. VENTANA PD-L1 (SP263) Assay staining of non-small cell lung cancer interpretation guide. Available from: https://www. rochebiomarkers.be/content/media/Files/ PD-L1_SP263_interpretation_guide NSCLC.pdf: 2019 (Accessed 2021 Jan 13).

15 Gagne A, Wang E, Bastien N, Orain M, Desmeules $P$, Page $S$, et al. Impact of specimen characteristics on PD-L1 testing in non-small cell lung cancer: validation of the IASLC PD$\mathrm{L} 1$ testing recommendations. J Thorac Oncol. 2019; $14: 2062-70$
16 Giunchi F, Degiovanni A, Daddi N, Trisolini R, Dell'Amore A, Agostinelli C, et al. Fading with time of PD-L1 immunoreactivity in nonsmall cells lung cancer tissues: a Methodological Study. Appl Immunohistochem Mol Morphol. 2018;26:489-94.

17 Kawachi H, Fujimoto D, Yamashita D, Fukuoka J, Kitamura Y, Hosoya K, et al. Association between formalin fixation time and programmed cell death ligand 1 expression in patients with non-small cell lung cancer. Anticancer Res. 2019;39:2561-7.

18 Kim MY, Koh J, Kim S, Go H, Jeon YK, Chung $\mathrm{DH}$. Clinicopathological analysis of PD-L1 and PD-L2 expression in pulmonary squamous cell carcinoma: comparison with tumor-infiltrating T cells and the status of oncogenic drivers. Lung Cancer. 2015;88:24-33.

19 Mansfield AS, Aubry MC, Moser JC, Harrington SM, Dronca RS, Park SS, et al. Temporal and spatial discordance of programmed cell death-ligand 1 expression and lymphocyte tumor infiltration between paired primary lesions and brain metastases in lung cancer. Ann Oncol. 2016;27:1953-8.

20 Takamori S, Toyokawa G, Okamoto I, Takada K, Kozuma Y, Matsubara T, et al. Discrepancy in programmed cell death-ligand 1 between primary and metastatic non-small cell lung cancer. Anticancer Res. 2017;37:4223-8.

21 Kim HR, Cha YJ, Hong MH, Gandhi M, Levinson S, Jung I, et al. Concordance of programmed death-ligand 1 expression between primary and metastatic non-small cell lung cancer by immunohistochemistry and RNA in situ hybridization. Oncotarget. 2017;8: 87234-43.

22 Liu Y, Dong Z, Jiang T, Hou L, Wu F, Gao G, et al. Heterogeneity of PD-L1 expression among the different histological components and metastatic lymph nodes in patients with resected lung adenosquamous carcinoma. Clin Lung Cancer. 2018;19:e421-30.

23 Wang H, Agulnik J, Kasymjanova G, Fiset PO, Camilleri-Broet S, Redpath M, et al. The metastatic site does not influence PD-L1 expression in advanced non-small cell lung carcinoma. Lung Cancer. 2019;132:36-8.

24 Kitazono S, Fujiwara Y, Tsuta K, Utsumi H, Kanda S, Horinouchi H, et al. Reliability of small biopsy samples compared with resected specimens for the determination of programmed death-ligand 1 expression in nonsmall-cell lung cancer. Clin Lung Cancer. 2015;16:385-90.

25 Ilie M, Long-Mira E, Bence C, Butori C, Lassalle S, Bouhlel L, et al. Comparative study of the PD-L1 status between surgically resected specimens and matched biopsies of NSCLC patients reveal major discordances: a potential issue for anti-PD-L1 therapeutic strategies. Ann Oncol. 2016;27:147-53.

26 Gradecki SE, Grange JS, Stelow EB. Concordance of PD-L1 expression between core biopsy and resection specimens of non-small cell lung cancer. Am J Surg Pathol. 2018;42: 1090-4.
27 Elfving H, Mattsson JSM, Lindskog C, Backman M, Menzel U, Micke P. Programmed cell death ligand 1 immunohistochemistry: a concordance study between surgical specimen, biopsy, and tissue microarray. Clin Lung Cancer. 2019;20:258-e1.

28 Tsunoda A, Morikawa K, Inoue T, Miyazawa T, Hoshikawa M, Takagi M, et al. A prospective observational study to assess PD-L1 expression in small biopsy samples for nonsmall-cell lung cancer. BMC Cancer. 2019;19: 546.

29 Brahmer J, Reckamp KL, Baas P, Crinò L, Eberhardt WE, Poddubskaya E, et al. Nivolumab versus docetaxel in advanced squamous-cell non-small-cell lung cancer. N Engl J Med. 2015;373:123-35.

30 Borghaei H, Paz-Ares L, Horn L, Spigel DR, Steins M, Ready NE, et al. Nivolumab versus docetaxel in advanced nonsquamous nonsmall-cell lung cancer. N Engl J Med. 2015; 373:1627-39.

31 Rittmeyer A, Barlesi F, Waterkamp D, Park K, Ciardiello F, von Pawel J, et al. Atezolizumab versus docetaxel in patients with previously treated non-small-cell lung cancer (OAK): a phase 3, open-label, multicentre randomised controlled trial. Lancet. 2017;389:255-65.

32 Agilent. PD-L1 IHC 28-8 pharmDx Interpretation Manual. Available from: https://www. agilent.com/en/product/pharmdx/pd-l1-ihc28-8-overview: 2020 (Accessed 2021 Jan 13).

33 Agilent. PD-L1 IHC 22C3 pharmDx Testing for NSCLC. Available from: https://www.agilent.com/en/product/pharmdx/pd-l1ihc-22c3-pharmdx-testing-for-nsclc: 2020 (Accessed 2021 Jan 13).

34 Kim I, Kim A, Lee CH, Lee G, Kim A, Jo EJ, et al. Reliability of PD-L1 assays using small tissue samples compared with surgical specimens. Medicine. 2019;98:e14972.

35 Lozano MD, Abengozar-Muela M, Echeveste JI, Subtil JC, Bertó J, Gúrpide A, et al. Programmed death-ligand 1 expression on direct Pap-stained cytology smears from non-small cell lung cancer: comparison with cell blocks and surgical resection specimens. Cancer $\mathrm{Cy}$ topathol. 2019;127:470-80.

36 Bozzetti C, Squadrilli A, Nizzoli R, Lagrasta C, Gasparro D, Majori M, et al. Optimizing PDL1 evaluation on cytological samples from advanced non-small-cell lung cancer. Immunotherapy. 2020;12:183-93.

37 Yoshimura K, Inoue Y, Karayama M, Tsuchiya K, Mori K, Suzuki Y, et al. Heterogeneity analysis of PD-L1 expression and copy number status in EBUS-TBNA biopsy specimens of non-small cell lung cancer: comparative assessment of primary and metastatic sites. Lung Cancer. 2019;134:202-9.

38 Sakakibara R, Inamura K, Tambo Y, Ninomiya H, Kitazono S, Yanagitani N, et al. EBUSTBNA as a promising method for the evaluation of tumor PD-L1 expression in lung cancer. Clin Lung Cancer. 2017;18:527-534.e1. 
39 Skov BG, Skov T. Paired comparison of PDL1 expression on cytologic and histologic specimens from malignancies in the lung assessed with PD-L1 IHC 28-8pharmDx and PD-L1 IHC 22C3pharmDx. Appl Immunohistochem Mol Morphol. 2017;25:453-9.

40 Heymann JJ, Bulman WA, Swinarski D, Pagan CA, Crapanzano JP, Haghighi M, et al. PD-L1 expression in non-small cell lung carcinoma: comparison among cytology, small biopsy, and surgical resection specimens. Cancer Cytopathol. 2017;125:896-907.

41 Stoy SP, Rosen L, Mueller J, Murgu S. Programmed death-ligand 1 testing of lung cancer cytology specimens obtained with bronchoscopy. Cancer Cytopathol. 2018;126:1228.

42 Ilie M, Juco J, Huang L, Hofman V, Khambata-Ford S, Hofman P. Use of the 22C3 antiprogrammed death-ligand 1 antibody to determine programmed death-ligand 1 expression in cytology samples obtained from non-small cell lung cancer patients. Cancer Cytopathol. 2018;126:264-74.

43 Noll B, Wang WL, Gong Y, Zhao J, Kalhor N, Prieto V, et al. Programmed death ligand 1 testing in non-small cell lung carcinoma cytology cell block and aspirate smear preparations. Cancer Cytopathol. 2018;126:342-52.

44 Sakata KK, Midthun DE, Mullon JJ, Kern RM, Nelson DR, Edell ES, et al. Comparison of programmed death ligand-1 immunohistochemical staining between endobronchial ultrasound transbronchial needle aspiration and resected lung cancer specimens. Chest. 2018;154:827-37.

45 Munari E, Zamboni G, Sighele G, Marconi M, Sommaggio M, Lunardi G, et al. Expression of programmed cell death ligand 1 in non-small cell lung cancer: comparison between cytologic smears, core biopsies, and whole sections using the SP263 assay. Cancer Cytopathol. 2019;127:52-61.

46 Capizzi E, Ricci C, Giunchi F, Zagnoni S, Ceccarelli C, Gómez BUÁ, et al. Validation of the immunohistochemical expression of programmed death ligand 1 (PD-L1) on cytological smears in advanced non small cell lung cancer. Lung Cancer. 2018;126:9-14.

47 Hernandez A, Brandler TC, Zhou F, Moreira AL, Schatz-Siemers N, Simsir A. Assessment of programmed death-ligand 1 (PD-L1) immunohistochemical expression on cytology specimens in non-small cell lung carcinoma. Am J Clin Pathol. 2019;151:403-15.

48 Xu H, Bratton L, Nead M, Russell D, Zhou Z. Comparison of programmed death-ligand 1 (PD-L1) immunostain for nonsmall cell lung carcinoma between paired cytological and surgical specimens. Cytojournal. 2018;15:29.

49 Arriola AGP, Bashover E, Joseph C, Staerkel G, Wang WL, Roy-Chowdhuri S. The usefulness of various cytologic specimen preparations for PD-L1 immunostaining in nonsmall cell lung carcinoma. J Am Soc Cytopathol. 2018;7:324-32.
50 Grosu HB, Arriola A, Stewart J, Ma J, Bassett R, Hernandez M, et al. PD-L1 detection in histology specimens and matched pleural fluid cell blocks of patients with NSCLC. Respirology. 2019;24:1198-203.

51 Pak MG, Roh MS. Cell-blocks are suitable material for programmed cell death ligand-1 immunohistochemistry: comparison of cellblocks and matched surgical resection specimens in lung cancer. Cytopathology. 2019;30: 578-85.

52 Kuempers C, van der Linde LIS, Reischl M, Vogel W, Stellmacher F, Reck M, et al. Comparison of PD-L1 expression between paired cytologic and histologic specimens from nonsmall cell lung cancer patients. Virchows Arch. 2020;476:261-71.

53 Wang G, Ionescu DN, Lee CH, Hiruki T, Myers R, Shaipanich T, et al. PD-L1 testing on the EBUS-FNA cytology specimens of non-small cell lung cancer. Lung Cancer. 2019;136:1-5.

54 Hendry S, Byrne DJ, Christie M, Steinfort DP, Irving LB, Wagner CA, et al. Adequate tumour cellularity is essential for accurate PDL1 immunohistochemistry assessment on cytology cell-block specimens. Cytopathology. 2020;31:90-5.

55 Song SG, Lee J, Koh J, Kim S, Chung DH, Jeon YK. Utility of PD-L1 immunocytochemistry using body-fluid cell blocks in patients with non-small-cell lung cancer. Diagn Cytopathol. 2020;48:291-9.

56 Dong Z, Liu Y, Jiang T, Hou L, Wu F, Gao G, et al. Cell block as a surrogate for programmed death-ligand 1 staining testing in patients of non-small cell lung cancer. J Cancer. 2020;11: 551-8.

57 Zou Y, Xu L, Tang Q, You Q, Wang X, Ding $\mathrm{W}$, et al. Cytology cell blocks from malignant pleural effusion are good candidates for PDL1 detection in advanced NSCLC compared with matched histology samples. BMC Cancer. 2020;20:344.

58 Jug R, Giovacchini CX, Liu B, Green CL, Clarke JM, Mahmood K, et al. EBUS-FNA cytologic-histologic correlation of PD-L1 immunohistochemistry in non-small cell lung cancer. J Am Soc Cytopathol. 2020;9:485-93.

59 Gagne A, Orain M, Ionescu D, Tsao MS, Joubert D, Joubert P. Comprehensive assessment of PD-L1 immunohistochemistry on paired tissue and cytology specimens from nonsmall cell lung cancer. Lung Cancer. 2020; 146:276-84.

60 Lou SK, Ko HM, Kinoshita T, MacDonald S, Weiss J, Czarnecka-Kujawa $\mathrm{K}$, et al. Implementation of PD-L1 22C3 IHC pharmDxTM in cell block preparations of lung cancer: concordance with surgical resections and technical validation of CytoLyt $(\mathrm{R})$ prefixation. Acta Cytol. 2020;64:577-87.
61 Bubendorf L, Conde E, Cappuzzo F, Langfort R, Schildhaus HU, Votruba J, et al. A noninterventional, multinational study to assess PD-L1 expression in cytological and histological lung cancer specimens. Cancer Cytopathol. 2020;128:928-38.

62 Koomen BM, van der Starre-Gaal J, Vonk JM, von der Thusen JH, van der Meij JJC, Monkhorst $\mathrm{K}$, et al. Formalin fixation for optimal concordance of programmed death-ligand 1 immunostaining between cytologic and histologic specimens from patients with nonsmall cell lung cancer. Cancer Cytopathol. 2021 Apr;129(4):304-17.

63 Jain D, Mathur SR, Iyer VK. Cell blocks in cytopathology: a review of preparative methods, utility in diagnosis and role in ancillary studies. Cytopathology. 2014;25:356-71.

64 Jain D, Sukumar S, Mohan A, Iyer VK. Programmed death-ligand 1 immunoexpression in matched biopsy and liquid-based cytology samples of advanced stage non-small cell lung carcinomas. Cytopathology. 2018;29:550-7.

65 Gosney JR, Haragan A, Chadwick C, Giles TE, Grundy S, Tippett V, et al. Programmed death ligand 1 expression in EBUS aspirates of nonsmall cell lung cancer: is interpretation affected by type of fixation? Cancer Cytopathol. 2020;128:100-6.

66 Russell-Goldman E, Kravets S, Dahlberg SE, Sholl LM, Vivero M. Cytologic-histologic correlation of programmed death-ligand 1 immunohistochemistry in lung carcinomas. Cancer Cytopathol. 2018;126:253-63.

67 McLaughlin J, Han G, Schalper KA, CarvajalHausdorf D, Pelekanou V, Rehman J, et al. Quantitative assessment of the heterogeneity of PD-L1 expression in non-small-cell lung cancer. JAMA Oncol. 2016;2:46-54.

68 Fernandez-Bussy S, Pires Y, Labarca G, Vial MR. PD-L1 expression in a non-small cell lung cancer specimen obtained by EBUS-TBNA. Arch Bronconeumol. 2018;54:290-2.

69 Vigliar E, Malapelle U, Iaccarino A, Acanfora G, Pisapia P, Clery E, et al. PD-L1 expression on routine samples of non-small cell lung cancer: results and critical issues from a 1-year experience of a centralised laboratory. J Clin Pathol. 2019;72:412-7.

70 Gandini S, Massi D, Mandalà M. PD-L1 expression in cancer patients receiving anti PD-1/PD-L1 antibodies: a systematic review and meta-analysis. Crit Rev Oncol Hematol. 2016;100:88-98.

71 Evans M, O'Sullivan B, Hughes F, Mullis T, Smith M, Trim N, et al. The Clinicopathological and molecular associations of PD-L1 expression in non-small cell lung cancer: analysis of a series of 10,005 cases tested with the 22C3 assay. Pathol Oncol Res. 2020;26:79-89.

72 Velcheti V, Patwardhan PD, Liu FX, Chen X, Cao X, Burke T. Real-world PD-L1 testing and distribution of PD-L1 tumor expression by immunohistochemistry assay type among patients with metastatic non-small cell lung cancer in the United States. PLoS One. 2018; 13:e0206370. 